\title{
German Politics auf Deutsch: Teaching Comparative Politics in a Language Across the Curriculum Format*
}

\author{
Mark Hallerberg, University of Pittsburgh \\ Bettina Cothran, Georgia Tech
}

$\mathrm{O}$ ne goal of any comparative politics course is to educate students about another part of the world. Students may learn specifically about how a parliamentary system functions in the United Kingdom, for example, or how Brazilian peasants pressure their government for land reform, but the general hope is that students leave college with a more sophisticated view of the outside world. Because it is difficult to make more theoretical concepts come alive without some understanding of a given country's culture, institutions, and society, knowledge of a country's language can be an important requisite for achieving this objective. Indeed, most political science departments in the United States require some minimal level of language training for their degree students.

At American universities, students learn languages and study politics in relative isolation from one another. During the first two years of language instruction, such instruction focuses on oral and written expression as well as on elementary com-

Mark Hallerberg is an assistant professor at the University of Pittsburgh. His research focuses on the political economy of the European Union, fiscal policy, German politics, and the effects of globalization on domestic politics.

Bettina Cothran is an associate profes sor of modern languages at Georgia Tech. Professor Cothran has been teaching Business German since 1976, developing courses and teaching materials as well as publishing on this topic. As director of the Key Center for Business German in the Southeast, she also administers the international Business German examinations. prehension. Once a student has a solid foundation in a given language, her sole outlet to develop her skills further is usually to stay inside the language department and take courses developed by professors whose principle interests lie in literature. Similarly, while political science professors teach courses whose list of countries span the globe, they usually attempt to keep foreign words and phrases to a minimum. Too much country-specific jargon in another language confuses and frustrates students.

This article explores one way professors from both fields can work together to increase students' understanding of a given country's language and politics. Language Across the Curriculum (LAC) brings language training into fields where it is not usually part of the course. Anderson (1994) described five different ideal types, ranging from a minimalist "trailer approach," where the course is basically taught in English and selected materials are covered in German in an additional hour of class time, to the most ambitious approach, where the entire course is taught in German and one political science professor and one language professor are in class at all times.

In order to encourage others to offer such courses and to illustrate potential problems and solutions, we will detail our experiences coteaching a course in German on post-war German politics at Georgia Tech. We believe this model can easily be applied to other languages as well as to other subfields of political science.

\section{Description of the Course}

Before proceeding further, it is important to describe both the goals and the content of the course we offer at Georgia Tech. We have two complementary goals: To further the students' comprehension of a language in their field of professional expertise and to increase their understanding of a given country's political system. Moreover, we want to increase students' knowledge beyond what they could gain in a standard language or comparative politics course. One can best reach these goals with the active participation of professors from both fields.

The target audience of the course makes cooperation essential. We expect the students to have taken a minimum of two years of German (and preferably three or more years), and to treat the course as a seminar to develop their language skills further. We expect to have no native German speakers in the class. Indeed, we actively discourage native speakers from participating because they can destroy the balance of the class and intimidate nonnative speakers. ${ }^{2}$ Nonnative speakers require additional help with vocabulary as well as with their written and spoken expression that a nonspecialist in language training is not equipped to provide. They also require differential levels of assistance-nonnative speakers enter the class with different levels of language ability. A language professor used to dealing with this situation can design the course more appropriately for the students. Similarly, students' knowledge of political science differs. One must convey the 
important role theory plays in the social sciences to teach the course effectively. A political science professor is best able to provide this material.

We are not suggesting that a political science professor who knows another language simply take her notes from a standard comparative politics course and translate them, or that a language professor merely supplement her standard seminar on a country's modern culture. Both are trained to recognize and meet different concerns from the students, and the skills that they teach, while complementary, are best developed with the professors from the respective fields. Our cooperation assures that readings and lectures reflect both of our goals and that neither of us treads too far from our field of expertise.

The course, a survey of postwar German politics titled "Deutsche Politik der Gegenwart (Contemporary German Politics)," concentrates on the development of the two Germanies from May 7, 1945, to their eventual reunification. In the last third of the class, we explore issues that confront the country today, such as high unemployment, the continued problems associated with reunification, Germany's role in the European Union, and environmental issues. We had twenty students, with roughly half enrolled under the modern language designation and half under the School of International Affairs designation. They had had between two and four years of German before taking our course. No single textbook sufficed for the course. College-level German-language political science textbooks assume too much background in German history and politics, so we found it necessary to rely upon original specches, short articles, and, when appropriate, current material on the Internet.

Most readings and all discussions and assignments were in German. The use of the "foreign" language yiclds several advantages over a traditional area studies course. Some concepts do not translate well into English, or they have a somewhat. different meaning in German than one would first presume. For exam- ple, "Die Machtergreifung" is generally translated as "seizure of power." In contemporary German usage, however, it now refers to only one particular seizure of power, namely Adolf Hitler's seizure of the state in 1933. Other concepts that do translate may be misunderstood out of context. A newspaper article making a reference to the "zero hour (Stunde Null)," for example, has little relevance to a student who knows the literal meaning but has not learned about the postwar period and knows that the term refers to the new beginning in Germany after the fall of Hitler. Likewise, while Americans have at least some vague idea why "Watergate" was important and can follow without further explanation derivatives like "Irangate," Germans have defining scandals in their postwar history like the Spiegel Affair and the Guillaume Affair, with the latter leading to the resignation of a chancellor. Since the instructional materials are in German, students can catch nuances that they would miss in translations in an English-only class. Konrad Adenauer's Prussian mannerisms, for example, do not come through reading a translated speech in a textbook.

On the political science side, the course offers the possibility of providing a deeper consideration of theories not based on a single case. We discuss the role of Germany in a larger state system with rival superpowers as well as how institutional changes from Weimar Germany to modern Germany have shaped the nature of the political climate and debate.

\section{Elements of a Successful Course}

Professors who teach this type of course must overcome two significant problems: Students have considerable difficulty reading texts and hearing speeches written for native speakers and students lack basic political knowledge that even most of their counterparts at a high school age possess in the country under study. Based on our experience, we suggest the following approaches to alleviate these problems.

\section{Group Work}

During each class session we divided the students into small groups that forced all of the students to discuss the readings and lecture in German. Both professors circulated among the groups and listened in on the discussions, offering individual assistance to students who nceded it and monitoring what the students said to make sure we were not moving too quickly through the material.

\section{Prepare Detailed Study Guides with Terms}

In our course, Bettina Cothran prepared detailed vocabulary lists and study guides, while Mark Hallerberg provided lists with key political terms and phrases. We discovered during the first week of the class that the students' knowledge base in German politics was extremely limited. Personalities like the first general secretary of the Communist Party in East Germany, Walter Ulbricht, or the first postwar leader of the Social Democratic Party, Kurt Schumacher, were simply names on a board to the students. It is difficult to convey theoretical concepts about how electoral systems or coalition governments function if the students do not know the parties or the parties' leaders. While this problem arises in all comparative courses that get into any detail about the cases, the situation was exacerbated in our class by the language barrier. It takes more time to illustrate even the most basic of concepts when few of the students understand everything the professor says.

\section{Rely on What the Students Already Know}

One of the main themes of our course was the influence the Allies had on the structure of German political institutions. All the students had read something about the end of World War II, but they had not thought deeply about the war's implications. Questions that ran throughout the course included why 
the Allies, and specifically the Americans, would want to establish a given institution in the form it took and to what extent the Germans were independent and how did the relationship change over time. We developed answers to these questions using the knowledge the students already had about the end of the war. We asked them questions about what they knew had happened in the period and then added the new material.

\section{Repeat Key Concepts}

When lecturing to students in a foreign language, professors must include numerous examples and repeat the key point in different words to assure that the students have understood the material. Different assignments intended to achieve the same outcome must be given. Readings during the first week of the course stressed the situation facing citizens in Cologne and Dresden, cities that ended the war in western and eastern (British and Russian) occupation zones. The students then read short passages written, respectively, from American, British, and Russian perspectives. They watched videos in German about the period and listened to radio broadcasts. Repetition of the theme in different formats enriched the learning process and assured that the language hurdle did not prevent the students from grasping the key concepts.

\section{Use Internet Resources}

Material in German is now widely available on the Internet, and we encouraged our students to reference this material when doing their assignments. At the end of the course, we required students to support a given political party in the upcoming elections. Since all the political parties have web sites, students were expected to read the party manifestos online, to write papers advocating a party's position, and to participate in oral debates with other students in their class. While completing these assignments, students were asked to keep in mind not only the potential supporters for a given party, but also what type of voter a given party expects will be checking their web page. Only about $7 \%$ of the German population has Internet access. Consequently, the likely readers of the Social Democratic Party's (SPD) webpage are fairly wealthy and young. While the SPD targets such an audience online, its homepage content would be different if Ruhr Valley coal miners were regularly checking its page. This bias is not necessarily a disadvantage - students liked the youngish designs that most parties used-but the students do need to be aware of the particular slant of Internet sources.

\section{Evaluation of Students}

Professors should be aware of the restrictions on how much information students can evaluate in in-class assignments. Students are simply much slower writers and thinkers in a second language. We found that students did a much better job on essays written outside of class than on in-class assignments. These exercises gave the students time to concentrate both on the language and on the content. As in a standard language course, we also expected students to rewrite their essays and to correct their grammar once the professors had read the papers. We encouraged the development of oral skills by reserving time during each class for questions and answers about the reading material. In grading, the language professor, Bettina Cothran, weighted the use of correct grammar and good style slightly more, while the reverse was true for the political scientist, Mark Hallerberg. With one or two exceptions, both arrived at the same grade.

In general, the students all improved their German during the class. The students also performed well in the assignments that stressed their development of political science theory.

\section{Evaluation of the Professors}

Conducting a successful course requires regular feedback from students. Several students came to us in the first days of the course convinced that the level of German was too high for them. Some handholding and positive reinforcement proved necessary to keep students involved and prevent them from becoming frustrated. Regular anonymous evaluations, as well as informal questions in English about how they were doing after class, gave students ample opportunity to voice their concerns.

In general, most students were very enthusiastic about this course and expressed a desire to enroll in another like it. In written evaluations, they indicated that the most valuable aspect of the course was that it gave them the chance to learn vocabulary germane to their field of expertise.

\section{Conclusion}

In presenting this overview of our team teaching LAC experience, we glazed over several important issues. Successful team teaching, even in the same language and the same field, requires active collaboration among the professors. This collaboration is even more important when the professors come to the classroom from different disciplinary traditions. One issue is the cooperation between the two professors. The collaborative effort is quite extensive when one takes into account course preparation, flexibility during the teaching based on student reception of the materials, and grading. The last issue especially requires a good personal rapport between the professors. We found it essential to present a "united front" to the students. These issues are important as well, and professors interested in pursuing similar courses are encouraged to do further reading (sce esp., Davis 1995).

While we described a situation in which two professors from different fields cooperated in developing and teaching a course, we are well aware that many universities have real concerns about the scarcity of resources. Having two professors in one room teaching 20 students is a real luxury at many schools. Both departments and the dean's office must view this course as a welcome addition in fulfilling the international mission of 
the university. When such support is lacking, professors should consider whether some of the goals of contextualizing the comparative politics component of the course can be reached by assigning additional materials in the appropriate language.

\section{Notes}

*The authors would like to thank the German Academic Exchange Service (DAAD) and the Georgia Tech Foundation for their financial support of the development of the course discussed in the article.

\section{References}

Anderson, Keith O. 1994. "German Across the Curriculum." In Handbook for German in Business and Technology, ed. Bettina Cothran. Cherry Hill, NJ: American Association of Teachers of German.
This option may be the only one available to professors at many universities. Yet, we believe that this option, as useful as it is, does indeed supplement an additional course. We hope that we have indicated in this article why a complete course in comparative politics in the native language leads to additional value added. Learning political concepts in a country's native language simply leads to a more complete understanding of a given country's political culture.
1. For examples of the application of this approach to other disciplines like business and engineering, see Grandin and Hedderich (1994).
Davis, James R. 1995. Interdisciplinary Courses and Team Teaching: New Arrangements for Learning. Phoenix: Oryx Press.

Grandin, John M., and Norbert Hedderich. 1994. "Building an Interdisciplinary Busi-
2. An independent study project is a more appropriate venue for a native speaker. ness German Program: The University of Rhode Island." In Handbook for German in Business and Technology, ed. Bettina

Cothran. Cherry Hill, NJ: American Association of Teachers of German. 